\title{
The Involvement of AMPA Receptor in the Antidepressant-like Effects of the Portulaca Oleracea L. Extract in Mice
}

\author{
Soo-Jin Park, Min-Ji Choi, Sun-Yong Chung*, Jong-Woo Kim*, Seung-Hun Cho ${ }^{\dagger}$ \\ Department of Neuropsychiatry, College of Korean Medicine, Kyung-Hee University, \\ "Department of Neuropsychiatry, Hospital of Korean Medicine, Kyung Hee University Hospital at Gangdong, \\ ${ }^{+}$Department of Neuropsychiatry, Hospital of Korean Medicine, Kyung Hee University Medical Center
}

\begin{abstract}
Objectives :

The development of natural drugs with antidepressant effects is important and needed. This study was performed to investigate the antidepressant-like effects of the distilled water extract of Portulaca oleracea L. (POL) in a mouse model and to investigate the role of $\alpha$-amino-3-hydroxy-5-methyl-4-isoxazole-propionic acid (AMPA) receptors in producing these antidepressant-like effects.
\end{abstract}

\section{Methods :}

The forced swim test (FST) and tail suspension test (TST) were used to investigate the behavioral anti-depressive-like effects of POL in mice. Additional behavioral experiments with 2,3-dihydroxy-6-nitro-7-sulfamoyl-benzo[f]quinoxaline-2,3dione, an AMPA receptor antagonist, were undertaken to determine the involvement of the antidepressant-like properties of POL in AMPA receptor throughput.

\section{Results :}

Oral administration of the POL extract $(100 \mathrm{mg} / \mathrm{kg}) 1 \mathrm{~h}$ prior to testing significantly reduced the immobility times in the FST and TST. The antidepressant-like effects of the POL extract were not increased in a dose-dependent manner. Pre-treatment with NBQX significantly attenuated the reduction in immobility time induced by the POL extract in the FST.

\section{Conclusions :}

The distilled water extract of POL has antidepressant-like effects, which may be related to AMPA receptor. Pre-treatment with NBQX significantly attenuates the reduction in immobility time induced by the POL extract in the FST.

\section{Key Words:}

Antidepressant, Portulaca oleracea L. (POL), Forced swim test (FST), Tail suspension test (TST), Depression, $\alpha$-amino3-hydroxy-5-methyl-4-isoxazole-propionic acid (AMPA).

Received : August 29, 2013; Accepted : September 23, 2013

Correspondence : Seung-Hun Cho, Department of Neuropsychiatry, College of Korean Medicine, Kyung-Hee University, Hoegidong, Dongdaemun-gu, Seoul, Korea.

Tel : +82-2-958-9188, Fax : +82-2-958-9183, E-mail : chosh@khu.ac.kr

This work was supported by a grant from the Kyung Hee University in 2012 (KHU-20121742). 


\section{Introduction}

Depression is one of the main mood disoder that affect mind, physical health, and behavior. It is thought to be caused by disturbance of monoamine neurotransmitters in the central nervous system (CNS). It was predicted as the second most common disease in 2020 by World Health Organization $(\mathrm{WHO})^{1)}$.

Depression may be mutually influenced by biological, genetic, social, and psychological factors. The biological etiology of depression involves the induction mediated by a biochemical imbalance of brain neurotransmitter. This knowledge has spurred drug development ${ }^{2-4)}$. Antidepressants currently in use include serotonin reuptake inhibitor (SSRI), serotonin-norepinephrine reuptake inhibitor (SNRI), norepinephrine-dopamine reuptake inhibitor $(\mathrm{NDRI})^{5-11)}$. Although most of the antidepressant medicines can ease depressive symptoms, they can also induce various unexpected side effects, and $30 \%$ of depressive patients do not respond properly to initial treatment ${ }^{12}$. SSRI side effects are less than those resulting from the use of tricyclic antidepressant (TCA) and monoamine oxidase inhibitors (MAOi). However, the side effects of SSRI are serious and include gastrointestinal problems, CNS excitement, and sexual dysfunction ${ }^{13)}$.

Alleviating these side effects is of paramount importance in the development of new antidepressant drugs. The possible development options include natural products ${ }^{14)}$. There is ample precedent for this, as many kinds of herbs have been used in traditional medicines to treat stress, sadness, anxiety, and depression ${ }^{15)}$.

POL has an anxiolytic-like effect, as apparent from the elevated plus-maze test (EPM) in mice.
This effect is mediated by the gamma-aminobutyric acid (GABA)ergic nervous system. This effect that was produced by a $70 \%$ ethanol extract of POL was blocked by an intra-peritoneal (i.p.) administration of $10 \mathrm{mg} / \mathrm{kg}$ of flumazenil, the GABAa antagonist, but not by the i.p. administration of the $0.3 \mathrm{mg} / \mathrm{kg}$ of the 5-hydroxytryptamine 1A (5-HT1A) antagonist WAY 100635. These results are evidence of the anxiolytic-like effect of POL, and suggest that this effect may be mediated through the GABAergic nervous system ${ }^{16)}$.

POL contains flavonoids, coumarines, monoterpene glycoside, several nitrogenous compounds such as N-trans-feruloyltyramine, dopamine (DA), dopa (Dopamine), norepinephrine (NA), and several alkaloid compounds ${ }^{17)}$. Furthermore, it has been demonstrated that NA and DA are the major bioactive components of $\mathrm{POL}^{18)}$. Capillary electrophoresis has proven to be a useful, simple, and rapid technique for identification and determination of DA and NA in herbal medicines and POL plants ${ }^{19)}$.

The collective foregoing results provide support for the view that POL might be effective in the treatment of depression. This study was performed to investigate the antidepressant-like effects of extract of POL in a behavioral despair animal model using the FST and TST. Both tests are commonly used to assess antidepressant activity ${ }^{20,21)}$.

Existing antidepressants are hampered by their lag period. For monoaminergic-based antidepressants, this treatment lag can be several weeks in duration. This limitation results in appreciable morbidity and high risk of suicidal behavior, especially in the first 9 days after beginning antidepressant treatment ${ }^{22)}$. Several previous studies aimed at identification and development more effective and well-tolerated drugs are underway, and are focused 
on glutamatergic-based therapeutics ${ }^{23-25)}$.

The roles of $\alpha$-amino-3-hydroxy-5-methyl-4-isoxazolepropionic acid (AMPA) receptors in depression and antidepressant treatment haven't been elucidated yet. The antidepressant fluoxetine positively modulates AMPA receptors ${ }^{26)}$. Positive AMPA receptor modulators (potentiators) manifest antidepressant-like effects in the FST and $\mathrm{TST}^{27)}$. Furthermore, 2,3-dihydroxy-6-nitro-7-sulfo amoylbenzo ( $f$ ) quinoxaline (NBQX), an AMPA receptor antagonist, blocks the antidepressant-like effect of NMDA receptor antagonists ${ }^{28,29)}$, which suggests that this effect may be mediated by an increased AMPA-to-NMDA receptor throughput in neuronal circuits $^{28)}$. The rapid and sustained antidepressantlike effects of ketamine in both the Learned helplessness paradigm, FST and TST are significantly blocked by $\mathrm{NBQX}^{30)}$.

Given the neurotransmitter involvement of $\mathrm{POL}^{16,17,19)}$, the present study investigated the possible involvement of POL with the AMPA receptor.

\section{Materials and Methods}

\section{Animals}

Male C57BL/6J mice (ORIENT BIO, Seoul, Korea) weighing 20 22 g, were used for behavioral and biochemical experiments. The mice were housed in acrylic cages $(22 \times 27 \times 12 \mathrm{~cm})$ with free access to water and food under an artificial 12-h light/dark cycle (lights on at 7:00 A.M. and off at 7:00 P.M.), at a constant temperature $\left(22 \pm 2^{\circ} \mathrm{C}\right)$ and humidity (40 $\pm 10 \%)$. Mice were housed in the departmental room for 1 week before testing to ensure adaptation to the new environment. All of the behavioral experiments were performed between 9:00 and
15:00. The present study was performed in accordance with the Kyung-Hee University Laboratory Animal Research Center guidelines for the care and use of laboratory animals.

\section{Preparation of POL extract}

POL was obtained from an oriental drug store (Jechon hanbang, Korea) and also from plants collected from Jechon, Korea, from May to July, 2011. The dried POL samples (600 g) were immersed in $2,500 \mathrm{ml}$ of distilled water (D.W) and boiled at $100^{\circ} \mathrm{C}$ for $1 \mathrm{~h}$. The DW extract was collected. The extracts were filtered through $110 \mathrm{~mm}$ filter paper (Advantec Inc., Tokyo, Japan). This process was performed once more $\left(100^{\circ} \mathrm{C}\right.$ reflux for $\left.40 \mathrm{~min}\right)$. The filtrate was evaporated on a rotary evaporator under reduced pressure and temperature, and freezing-dried to yield about $39.7 \%(\mathrm{w} / \mathrm{w})$ of the extract. The crude extracts were completely dissolved in distilled water immediately before use and administered to the mice orally $(100,500$, and $1,000 \mathrm{mg} / \mathrm{kg}$, p.o.). For each drug treatment, control mice received the respective vehicle alone.

\section{FST}

The FST was performed by an established process $^{31)}$. The apparatus consisted of a transparent Plexiglas cylinder (height $35 \mathrm{~cm}$, width $20 \mathrm{~cm}$ ) filled to a $20 \mathrm{~cm}$ depth with water at room temperature. Each mouse was kept in each cylinder of water between 23 and $25^{\circ} \mathrm{C}$. The duration of immobility during the last $4 \mathrm{~min}$ of the 6-min test were measured. Mobility was set as any movement beyond that needed to keep the head above water. At the end of the trial session, mice were trans- 
ferred from the water, dried with a paper towel, and put back in their home cages. To investigate dose-dependent antidepressant-like effects of the DW extract of POL, POL extracts $(100,500$, or 1,000 $\mathrm{mg} / \mathrm{kg}$ ) or DW were administered p.o. $1 \mathrm{~h}$ before the FST. Six to nine mice were used for each group.

\section{TST}

The TST was performed as described previously ${ }^{6}$ with modifications. Mice were hung by the tail from a metal rod using adhesive tape. The rod was fixed $45 \mathrm{~cm}$ above the surface of a table in a sound-blocked room. Each mouse was positioned at least $15 \mathrm{~cm}$ away from the nearest object. The test sessions were recorded for $6 \mathrm{~min}$, and the immobility time was determined by one observer. Mobility was defined as movement of the hind legs. To investigate dose-dependent antidepressant-like effects of the DW extract of POL, POL extracts (100, 500 , or $1,000 \mathrm{mg} / \mathrm{kg}$ ) or DW were administered p. $\mathrm{o} .1 \mathrm{~h}$ before the test. Five to seven mice were used for each group.

\section{Statistical analysis}

Statistical analyses were executed using SPSS ver. 18 computer software (SPSS Inc., USA). Data were analyzed using one-way analysis of variance (ANOVA). Tukey HSD and LSD post hoc test were utilized to compare significant ANOVA results. Results are presented as the mean \pm SEM. All statistics were 2-tailed. Statistical significance was set at $\mathrm{p}<0.05$.

\section{Results}

\section{Antidepressant-like effects of POL extract in the FST}

To study the dose-dependent antidepressant-like effects of POL DW extract, the FST was used. Mice were administered with DW or POL extract (100, 500 , or $1,000 \mathrm{mg} / \mathrm{kg}$ ) $1 \mathrm{~h}$ before the test (Fig. 1). An oral administration of POL extract $(100 \mathrm{mg} / \mathrm{kg})$ significantly decreased the immobility times in the FST $(p<0.05)$, although extract concentrations of $500 \mathrm{mg} / \mathrm{kg}$ and $1,000 \mathrm{mg} / \mathrm{kg}$ did not decrease significantly the immobility times. The results indicated that the antidepressant-like effect was not dose-dependent.

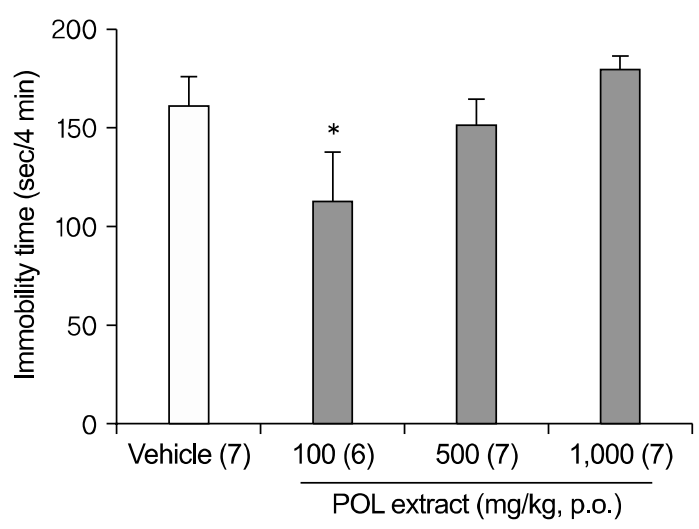

Fig. 1. Dose-related antidepressant-like effects of POL extract in the FST. An oral administration ( $1 \mathrm{~h}$ before the test) of POL extract $100 \mathrm{mg} / \mathrm{kg}$ significantly reduced the immobility times in the FST. Data represent means $\pm S E M$. The number of mice per group is indicated in each individual graph. ${ }^{*} p<0.05$ versus vehicle (DW) treated, LSD post hoc tests.

POL: Portulaca oleracea L, FST: The forced swim test, SEM: standard error mean, DW: distilled water, LSD post hoc tests: least significance difference post hoc tests. 


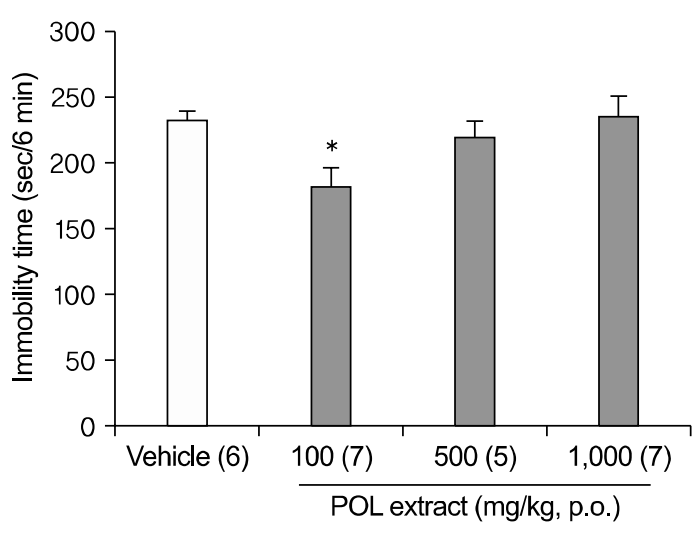

Fig. 2. Dose-related antidepressant-like effects of POL extract in the TST. An oral administration ( $1 \mathrm{~h}$ before test) of $\mathrm{POL}$ extract $100 \mathrm{mg} / \mathrm{kg}$ significantly reduced the immobility times in the TST. Data represent $\pm S E M$. The number of mice per group is indicated in each individual graph. ${ }^{*} p<0.05$ versus vehicle (DW) treated, Tukey HSD post hoc tests.

POL: Portulaca oleracea L, FST: The forced swim test, SEM: standard error mean, DW: distilled water, Tukey HSD post hoc test: Tukey honestly significant difference post hoc test.

A

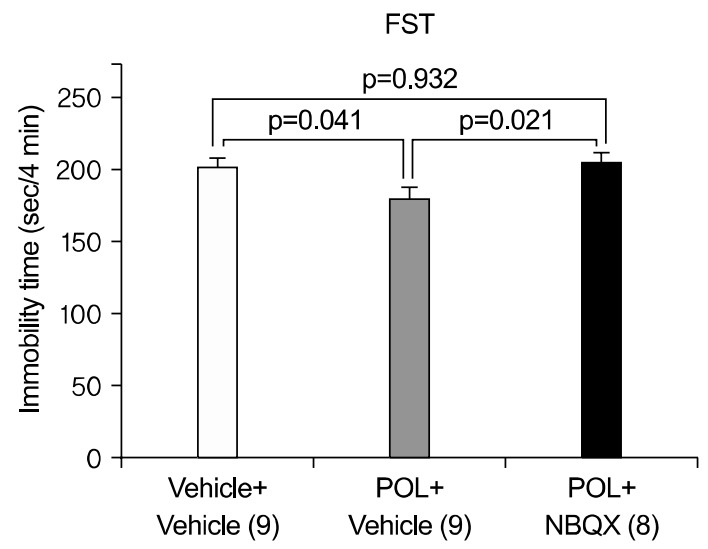

\section{Antidepressant-like effects of POL extract in the TST}

Mice were fed with DW or POL extract (100, 500, and $1,000 \mathrm{mg} / \mathrm{kg}$ ) $1 \mathrm{~h}$ before the test (Fig. 2). An oral administration of $100 \mathrm{mg} / \mathrm{kg}$ POL extract significantly decreased the immobility times in the TST $(\mathrm{p}<0.05)$, although the results at $500 \mathrm{mg} / \mathrm{kg}$ and $1,000 \mathrm{mg} / \mathrm{kg}$ were not significant, meaning that the antidepressant-like effect of POL extract did not ascend dose-dependently.

\section{Effects of AMPA receptor blockade on the antidepressant-like effects of POL extract in the FST}

We administered $100 \mathrm{mg} / \mathrm{kg}$ POL extract or DW to mice $1 \mathrm{~h}$ before the FST, followed by i.p. injection of the AMPA receptor antagonist NBQX or vehicle $40 \mathrm{~min}$ prior to testing. We selected a dose

B

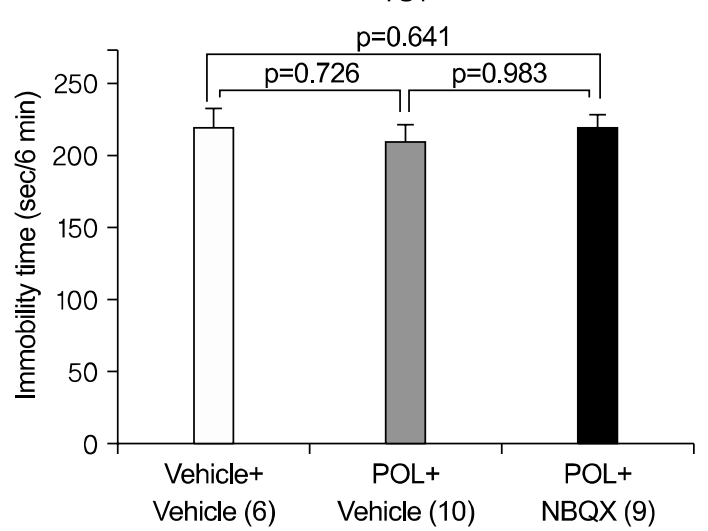

Fig. 3. Effects of AMPA receptor blockade on the antidepressant-like effects of POL extract in the FST. NBQX pretreatment $(100 \mathrm{mg} / \mathrm{kg}, 40 \mathrm{~min}$ before the test, i.p.) significantly attenuated the reduction in immobility time induced by POL extract $(100 \mathrm{mg} / \mathrm{kg}$, 1h before test, p.o.) in the FST (A), but it did not significantly attenuated the reduction in immobility time in the TST (B). Vehicle of NBQX is saline. Data represent mean \pm SEM. The number of mice per group is indicated in each individual graph, were compared with Tukey HSD post hoc tests. AMPA: $\alpha$-amino-3-hydroxy-5-methyl-4-isoxazolepropionic acid, POL: Portulaca oleracea L, FST: The forced swim test, NBQX: 2,3-dihydroxy-6-nitro-7-sulfo amoylbenzo (f) quinoxaline, SEM: standard error mean, Tukey HSD post hoc test: Tukey honestly significant difference post hoc test. 
of $10 \mathrm{mg} / \mathrm{kg}$ of NBQX because a dose in this range has been demonstrated to decrease AMPA-induced seizures in mice ${ }^{11)}$. NBQX pretreatment significantly attenuated the reduction in immobility time induced by POL extract in the FST (Fig. 3A, p $<0.05)$. Post hoc analysis revealed a significant effect of POL extract alone compared to the each of the other two groups (both $p<0.05$ ) and revealed no other significant differences. But, the antidepressant-like effect of the administration of 100 $\mathrm{mg} / \mathrm{kg}$ POL extract in the TST were not significantly attenuated by NBQX (Fig. 3B, p>0.05). Post hoc analysis indicates that the POL extract did not significantly act when applied alone compared to each of the other two groups $(\mathrm{p}>0.05)$. We omitted the group treated by DW and NBQX, because, for the FST there was no significant effect of NBQX alone in changing the immobility time in comparison with vehicle treated mice in previous studies ${ }^{30,32-34)}$.

\section{Discussion}

In developed countries, particularly in the East Asia, an abundance of material possessions that are the outcome of robust economic growth can create an imbalance with spiritual culture life. The resulting anxiety and depression can fuel the pathophysiology of most cases of mental illness. Indeed, a survey revealed that mental disease is more prevalent in societies that have achieved high economic growth (Committee of Neuropsychiatrical textbook in national Korean Medicine).

Scientific advancements have enabled a better understanding of the nature of anxiety and depression at the molecular level. Nonetheless, this knowledge has not translated into an effective treatment, and the incidence and prevalence of depres- sion have increased continuously. Typical antidepressants currently in use are SSRIs, SNRI, and 5 HT2 blockers ${ }^{7-11,35)}$. When used for a long time, the drugs can cause problems such as tolerance, dependence, and side effects. So, it is important to develop the natural drugs to overcome these problems.

Portulaca oleracea L. (POL) is grown widely in Korea and China. Also, the various parts of POL have been applied in the clinical treatment of various diseases in Oriental medicine. It is widely used not only as an edible plant, but also used as a traditional oriental herbal drug. It has long been used to alleviate pain and swelling. It also used for the treatment of dysentery with blood stools, and externally for boils and sores, eczema, erysipelas, and the bites of snakes and insects. POL displays anti-bacterial, anti-viral, anti-caducity, and anti-diabetes activities, along with enhancement of immunity ${ }^{20,32)}$.

Several reports reported the isolation of alkaloids, coumarins, terpenoids (ginkgolide A, B, and $\mathrm{C}$ and bilobalide), flavonoids, and fatty acids from $\mathrm{POL}^{17,33,34)}$. Interestingly, it reported that ginkgolides have a neuro-protective role against hypoxia-induced injury, which might be associated with their up-regulation of the expression of HIF-1-alpha in hypoxic neurons ${ }^{36}$. The ethanol extract from POL (EEPO) possesses notable anti-hypoxic activity, which might be related to promotion of the activity of the key enzymes in glycolysis and improving the level of ATP in hypoxic mice ${ }^{37)}$. It et al., recently reported ${ }^{38)}$ that POL possesses various effects on the nervous system, which include reduction in locomotor activity, anticonvulsant activity, inhibition of electrically stimulated contractions of nerve-muscle preparation, and muscle relaxant ac- 
tivity in conscious rats.

In addition, it was demonstrated that POL has an anxiolytic-like effect using an elevated plus maze test ${ }^{16)}$. However, as far as we know, there have been no studies concerning the antidepressant effect of POL.

In this study, we utilized the FST and TST, given their validation as a measure of the efficacy of various antidepressants. The FST is a behavioral despair animal model, and has been shown to be the most valid predictor of antidepressant action ${ }^{39-41)}$.

In the FST, oral administration ( $1 \mathrm{~h}$ before of test) of $100 \mathrm{mg} / \mathrm{kg}$ POL extract significantly reduced the immobility time. But, no significant effect was evident using 500, 1,000 mg/kg POL, indicating that the antidepressant-like effect of POL extract does not increase dose-dependently.

The TST was first described by Steru and his collegues ${ }^{6}$. In the test, the tail-suspended mouse moves actively at first. But, if depressed due to stress, it is more immobile initially, followed by alternating periods of mobility and immobility. Antidepressants reduce this period of immobility, allowing the TST to be used to verify antidepressant activity. Like the FST, in the case of TST, an oral administration ( $1 \mathrm{~h}$ before testing) of $100 \mathrm{mg} / \mathrm{kg}$ POL extract significantly reduced the immobility time. But, no significant effect was evident at POL concentrations of $500,1,000 \mathrm{mg} / \mathrm{kg}$, indicating that the antidepressant-like effect of POL extract did not increase with increasing dose.

There are several possible explanations for the lack of a dose-dependent nature of POL. The 500, $1,000 \mathrm{mg} / \mathrm{kg}$ doses of POL may have been excessive and toxic/sedative. This explanation is consistent with the anxiolytic-like effect of POL via the GABAergic nervous system ${ }^{16)}$.
Although multiple classes of medicines with monoamine-based mechanisms of action exist for the treatment of depression, many patients fail to achieve a sustained remission of depressive symptoms. The demands for improved pharmacotherapies for treatment-resistant depression suggest a great need for the development of new compounds with novel mechanisms of action such as glutamate transmission and related pathways ${ }^{42)}$.

Modulation of the AMPA receptor subclass of glutamate receptors has been connected to the mechanism of action of antidepressant medications, as well as a target for future medications ${ }^{44-48)}$. Recently, there has been demonstrated that the antidepressant-like effects of ketamine in the FST, as well as MK801, the NMDA antagonist and Ro256981, the NR2B antagonist are prevented by pre-administration of $\mathrm{NBQX}^{28)}$. Ketamine is of great interest because its' efficacy includes rapid and relatively sustained antidepressant effects, and it is the only known drug or somatic treatment that results in such a dramatic and extended response with a single. However, adverse reactions may take place despite their acute and mostly chronic use, including neurotoxic effects, cognitive deficits, and psychotomimetic effects. Therefore, it is necessary and important to discover potential therapeutic agents derived from natural sources that exhibit antidepressant-like effect related to AMPA receptor activation.

Presently, pre-treatment with NBQX significantly attenuated the reduction in immobility time induced by POL extract in the FST. This indicates the possibility that antidepressant effect of POL is related with AMPA receptor activation.

But, pre-treatment with NBQX did not significantly attenuate the reduction in immobility time 
induced by POL extract in the TST. In our experiments, the experimental process was videotaped to accurately determine the immobility time. However, $3-4$ mice (especially in the control group) could not be videotaped due to equipment problems. Thus, the differing numbers of mice in the experimental groups hamper the statistical significance of the results. Otherwise, it could mean that the antidepressant effect of POL might not be related with AMPA receptor activation. However, considering the problem of experimental course, it is difficult to affirm that the antidepressant effect of POL is never related with AMPA receptor activation.

Therefore, further studies are needed to establish those constituents that contribute to the antidepressant-like effects of POL extract. Additional animal studies, such as the Learned helplessness paradigm, are also required to demonstrate the rapid and sustained antidepressant-like effects of POL extract. To clarify the effect of POL on glutamatergic systems, a well-designed study is needed.

\section{Conclusion}

This study was carried out to investigate the antidepressant-like effects of DW extract of POL in behavioral despair models examined using FST and TST, and to discern whether the antidepressant-like properties of POL involve AMPA receptor throughput. An oral administration ( $1 \mathrm{~h}$ before testing) of $100 \mathrm{mg} / \mathrm{kg}$ POL extract significantly reduced the immobility times in the FST and TST (both $\mathrm{p}<.05$ ). NBQX pretreatment $(10 \mathrm{mg} / \mathrm{kg}, 40 \mathrm{~min}$ before testing, i.p.) significantly attenuated the reduction in immobility time induced by POL extract (100 mg/ $\mathrm{kg}, 1 \mathrm{~h}$ before testing, p.o.) in the FST. Post hoc analysis revealed a significant effect of POL extract alone compared to either of the other two groups (both $\mathrm{p}<.05$ ) and no other significant differences. In conclusion, this study demonstrates that the DW extract of POL has antidepressant-like effects, and suggest that this effect might be related to the AMPA receptor.

\section{References}

1. WHO. WHO World Health Statistics. Ten Statistical Highlights in Global Public Health; 2010.

2. Committee of Neuropsychiatrical Textbook in National Korean Medicine. Psychiatry of Korean Medicine. Seoul, Jibmundang; 2007;256-65, 47286, 493-502.

3. Duman RS, Heninger GR, Nestler EJ. A Molecular and Cellular Theory of Depression. Arch Gen Psychiatry. 1997;54(7):597-606.

4. Kim YG. Neurobiology of Depression. Korean Medical Association Paper. 2003;9:783-9.

5. Butler SG, Meegan MJ. Recent Developments in the Design of Anti-depressive Therapies;targeting the Serotonin Transporter. Curr Med Chem. 2008;15(17):1737-61.

6. Steru L, Chermat R, Thierry B, Simon P. The Tail Suspension Test: A New Method for Screening Antidepressants in Mice. Psychopharmacology (Berl). 1985;85(3):367-70.

7. Bymaster FP, McNamara RK, Tran PV. New Approachest Developing Antidepressants by Enhancing Monoaminergic Neurotransmission. Expert Opin Investig Drugs. 2003;12(4):531-43.

8. Segrave R, Nathan PJ. Pindolol Augmentation of Selective Serotonin Reuptake Inhibitors: Accounting for the Variability of Results of Placebo-controlled Double-blind Studies in Patients with Major Depression. Hum Psychopharmacol. 2005; 20(3):163-74.

9. Cowen PJ. A Role for 5-HT in the Action of Antidepressant Drugs. Pharmacol Ther. 1990; 46(1):43-51.

10. Anttila SA, Leinonen EV. A Review of the Pharmacological and Clinical Profile of Mirtaza- 
pine. CNS Drug Rev. 2001;7(3):249-64.

11. Masand PS, Gupta S. Long-term Side Effects of Newer-generation Antidepressants: S SRIS, Venlafaxine, Nefazodone, Bupropion, and Mirtazapine. Ann Clin Psychiatry. 2002;14(3):175-82.

12. Fava M, Rush AJ. Current Status of Augmentation and Combination Treatments for Major Depressive Disorder: a Literature Review and a Proposal for a Novel Approach to Improve Practice. Psychother Psychosom. 2006;75(3):139-53.

13. Pharmacology Session in the Council of Korean Pharmaceutical College: Pharmacology. Sin-il Inc.; 2005;212-27.

14. Newman DJ, Cragg GM, Snader KM. Natural Products as Sources of New Drugs Over the Period 1981-2002. J Nat Prod. 2003;66(7): 1022-37.

15. Zhang ZJ. Therapeutic Effects of Herbal Extracts and Constituents in Animal Models of Psychiatric Disorders. Life Sci. 2004;75(14):1659-99.

16. Lee $\mathrm{CH}$, Yoon $\mathrm{BH}$, Ryu JH, Jung JW. Anxiolytic-like Effects of Portulaca Oleraceae L. Using the Elevated Plus-maze in Mice. Oriental Pharmacy and Experimental Medicine. 2009;9(2):135-41.

17. Sakai N, Inada K, Okamoto M, Shizuri Y, Fukuyama Y. Portuloside A, a Monoterpene Glucoside, from Portulaca Oleracea. Phytochemistry. 1996; 42:1625-8.

18. Zhou J, Liu JW, Fu JW, et al. Isolation and Assaying of Polysaccharides in Portulaca Oleracea. Chin Tradit Herb Drug. 2001;32:124-5.

19. Yue M-E, Jiang T-F, Shi Y-P. Simultaneous Determination of Noradrenaline and Dopamine in Portulaca Oleracea L. by Capillary Zone Electrophoresis. Journal of Separation Science. 2005;28:360-4.

20. Porsolt RD, Bertin A, Jalfre M. Behavioral Despair in Mice: a Primary Screening Test for Antidepressants. Arch Int Pharmacodyn Ther. 1977; 229(2):327-36.

21. Le Pichon M, Porsolt RD, Jalfre M. Depression: a New Animal Model Sensitive to Antidepressant Treatments. Nature. 1977;266(5604):730-2.

22. Jick H, Kaye JA, Jick SS. Antidepressants and the Risk of Suicidal Behaviors. JAMA. 2004;292(3):
$338-43$.

23. Mineur YS, Picciotto MR, Sanacora G. Antidepressant-like Effects of Ceftriaxone in Male C57BL/6J Mice. Biol Psychiatry. 2007;61(2):250-2.

24. Paul IA, Skolnick P. Glutamate and Depression: Clinical and Preclinical Studies. Ann N Y Acad Sci. 2003;1003:250-72.

25. Sanacora G, Rothman DL, Mason G, Krystal JH. Clinical Studies Implementing Glutamate Neurotransmission in Mood Disorders. Ann N Y Acad Sci. 2003;1003:292-308.

26. Bleakman D, Alt A, Witkin JM. AMPA Receptors in the Therapeutic Management of Depression. CNS Neurol Disord Drug Targets. 2007;6(2):11726.

27. Alt A, Witkin JM, Bleakman D. AMPA Receptor Potentiators as Novel Antidepressants. Curr Pharm Des. 2005;11(12):1511-27.

28. Maeng S, Zarate CA Jr, Du J, Schloesser RJ, McCammon J, Chen G, et al. Cellular Mechanisms Underlying the Antidepressant Effects of Ketamine: Role of Alpha-amino-3-hydroxy-5-methylisoxazole-4-propionic acid Receptors. Biol Psychiatry. 2008;63(4):349-52.

29. Skolnick P. AMPA Receptors: a Target for Novel Antidepressants. Biol Psychiatry. 2008;63(4):3478.

30. Koike H, Iijima M, Chaki S. Involvement of AMPA Receptor in both the Rapid and Sustained Antidepressant-like Effects of Ketamine in Animal Models of Depression. Behav Brain Res. 2011; 224(1):107-11.

31. Chapman AG, Smith SE, Meldrum BS. The Anticonvulsant Effect of the non-NMDA Antagonists, NBQX and GYKI 52466, in mice. Epilepsy Res. 1991;9(2):92-6.

32. Zheng ZH, Dong ZH. Yu J. Modern Study of Traditional Chinese Medicine, Beijing University of Traditional Chinese Medicine. Xue Yuan Press, Beijing, China; 1997;753.

33. Liu LX, Howe P, Zhou YF, Xu ZQ, Hocart C, Zhang R. Fatty Acids and-carotene in Australian Purslane (Portulaca Oleracea) Varieties. Journal of Chromatography A. 2000;893:207-13.

34. Awad NE. Lipid Content and Antimicrobial 
Activity of Phenolic Constituents of Cultivated Portulaca Oleracea L. Bulletin of Faculty of Pharmacy of CairoUniversity. 1994;32:137-42.

35. Boyce P, Judd F. The Place for the Tricyclic Antidepressants in the Treatment of Depression. AustN Z J Psychiatry. 1999;33(3):323-7.

36. Zhu L, Wu XM, Yang L, Du F, Qian ZM. Up-regulation of HIF-1alpha Expression Induced by Ginkgolides in Hypoxic Neurons. Brain Research. 2007;1166:1-8.

37. Chen CJ, Wang WY, Wang XL, Dong LW, Yue YT, Xin HL, et al. Anti-hypoxic Activity of the Ethanol Extract from Portulaca Oleracea in Mice. Journal of Ethnopharmacology. 2009;124:246-50.

38. Radhakrishnan R, Zakaria MN, Islam MW, Chen HB, Kamil M, Chan K, et al. Neuropharmacological Actions of Portulaca Oleraceae Lv. sativa (Hawk). J Ethnopharmacol. 2001;76:171-6.

39. Pellow S, Chopin P, File SE, Briley M. Validation of Open-closed Arm Entries in an Elevated Plus-maze as a Measure of Anxiety in the Rat. J Neurosci Methods. 1985;14:149-67.

40. Bonetti EP, Pieri L, Cumin R, et al. Benzodiazepine Antagonist R15-1788: Neurological and Behavioral Effects. Psychopharmacology (Berl). 1982;78:8-18.

41. Overstreet DH, Pucilowski O, Rezvani AH, Janowsky DS. Administration of Antidepressants, Diazepam and Psychomotor Stimulants Further Confirms the Utility of Flinders Sensitive Line Rats as an Animal Model of Depression. Psychopharmacology (Berl). 1995;121(1):27-37.
42. Sanacora G, Treccanti G, Popolli M. Towards a Glutamate Hypothsis of Depression. An Emerging Frontier of Neuropsychopharmacology for Mood Disorders. Neuropharmacology. 2012;62:63-77.

43. Li X, Tizzano JP, Griffey K, Clay M, Lindstrom T, Skolnick P. Antidepressant-like Actions of an AMPA Receptor Potentiator (LY392098). Neuropharmacology. 2001;40(8):1028-33.

44. Alt A, Nisenbaum ES, Bleakman D, Witkin JM. A Role for AMPA Receptors in Mood Disorders. Biochem Pharmacol. 2006;71(9):1273-88.

45. Du J, Suzuki K, Wei Y, Wang Y, Blumenthal R, Chen Z. The Anticonvulsants Lamotrigine, Riluzole, and Valproate Differentially Regulate AMPA Receptor Membrane Localization: Relationship to Clinical Effects in Mood Disorders. Neuropsychopharmacology. 2007;32(4):793-802.

46. Li X, Witkin JM, Need AB, Skolnick P. Enhancement of Antidepressant Potency by a Potentiator of AMPA Receptors. Cell Mol Neurobiol. 2003; 23(3):419-30.

47. Martinez-Turrillas R, Frechilla D, Del Rio J. Chronic Antidepressant Treatment Increases the Membrane Expression of AMPA Receptors in Rat Hippocampus. Neuropharmacology. 2002;43(8): 1230-7.

48. Svenningsson P, Tzavara ET, Witkin JM, Fienberg AA, Nomikos GG, Greengard P. Involvement of Striatal and Extrastriatal DARPP-32 in Biochemical and Behavioral Effects of Fluoxetine (Prozac). Proc Natl Acad Sci U S A. 2002;99(5):3182-7. 